Article

\title{
Suppression of Oxygen Vacancy Defects in sALD-ZnO Films Annealed in Different Conditions
}

\author{
Ming-Jie Zhao ${ }^{1,2}{ }^{1}$, Zhi-Tao Sun ${ }^{1}$, Zhi-Xuan Zhang ${ }^{1}$, Xin-Peng Geng ${ }^{1}$, Wan-Yu Wu ${ }^{3}$, \\ Shui-Yang Lien ${ }^{1,2,3, *}$ and Wen-Zhang Zhu ${ }^{1,2}$ \\ 1 School of Opto-electronic and Communication Engineering, Xiamen University of Technology, \\ Xiamen 361024, China; 2015000077@xmut.edu.cn (M.-J.Z.); 18359225079@163.com (Z.-T.S.); \\ 1922031023@stu.xmut.edu.cn (Z.-X.Z.); gexipe@163.com (X.-P.G.); wzzhu@xmut.edu.cn (W.-Z.Z.) \\ 2 Fujian Key Laboratory of Optoelectronic Technology and Devices, Xiamen University of Technology, \\ Xiamen 361024, China \\ 3 Department of Materials Science and Engineering, Da-Yeh University, Changhua 51591, Taiwan; \\ wywu@mail.dyu.edu.tw \\ * Correspondence: sylien@xmut.edu.cn
}

Received: 8 August 2020; Accepted: 2 September 2020; Published: 4 September 2020

\begin{abstract}
Zinc oxide $(\mathrm{ZnO})$ has drawn much attention due to its excellent optical and electrical properties. In this study, $\mathrm{ZnO}$ film was prepared by a high-deposition-rate spatial atomic layer deposition (ALD) and subjected to a post-annealing process to suppress the intrinsic defects and improve the crystallinity and film properties. The results show that the film thickness increases with annealing temperature owing to the increment of oxide layer caused by the suppression of oxygen vacancy defects as indicated by the X-ray diffraction (XRD) and X-ray photoelectron spectroscopy (XPS) spectra. The film transmittance is seldom influenced by annealing. The refractive index increases with annealing temperature at $300-700{ }^{\circ} \mathrm{C}$, possibly due to higher density and crystallinity of the film. The band gap decreases after annealing, which should be ascribed to the decrease in carrier concentration according to Burstein-Moss model. The carrier concentration decreases with increasing annealing temperature at $300-700{ }^{\circ} \mathrm{C}$ since the oxygen vacancy defects are suppressed, then it increases at $800^{\circ} \mathrm{C}$ possibly due to the out-diffusion of oxygen atoms from the film. Meanwhile, the carrier mobility increases with temperature due to higher crystallinity and larger crystallite size. The film resistivity increases at $300-700{ }^{\circ} \mathrm{C}$ then decreases at $800{ }^{\circ} \mathrm{C}$, which should be ascribed primarily to the variation of carrier concentration.
\end{abstract}

Keywords: zinc oxide; oxygen vacancy defects; spatial atomic layer deposition; annealing; crystallinity

\section{Introduction}

Zinc oxide $(\mathrm{ZnO})$ is a popular material which has been paid much attention due to its excellent optical and electrical properties. The applications of $\mathrm{ZnO}$ include solar cells, light-emitting diodes (LEDs), gas sensors, and thin-film transistors (TFTs) [1-5]. ZnO film can be prepared by several techniques, such as pulsed laser deposition (PLD), sputtering, chemical vapor deposition (CVD), solution-based methods, atomic layer deposition (ALD), and molecular beam epitaxy (MBE) [6-11]. Among these techniques, ALD is distinguished for the self-limiting surface reaction between the precursors which is confined to the substrate surface. Therefore, it is possible to control the thin film growth at the atomic layer scale and hence high-quality thin film with precise control of film growth can be obtained by this technique. However, the deposition rate of conventional thermal ALD is somewhat low due to the long purge time needed to remove the residues of the reaction, which limits its application in industrial manufacturing. Recently, the disadvantage of thermal ALD has been 
avoided by the development of spatial ALD (sALD), where the precursors are dosed to separated zones of the reactor divided by a nitrogen gas curtain. When the substrate moves horizontally under the precursor spray heads, it was exposed to the precursors successively and the reaction occurs on its surface. In this way, the purge step can be omitted $[12,13]$. Therefore, the atmospheric sALD process is more cost-efficient than other vacuum-based process. Therefore, sALD is emerging as a promising technique for mass manufacture owing to the possible high throughput.

Generally, the properties of $\mathrm{ZnO}$ film strongly depend on the intrinsic defects. The defective structure of $\mathrm{ZnO}$ has received much attention for various optoelectronic and catalytic devices. However, the oxygen defects in $\mathrm{ZnO}$ film can be favorable or harmful depending on their states and applications. As one of the major defects, the oxygen vacancy defects in oxide film may act as either donor or acceptor in the band gap depending on their coordinating conditions and charged states [14-17]. On one hand, oxygen vacancy defects with high coordination or that are negatively charged serve as shallow donors that donate free carriers to the conduction band and contribute to the conduction of the film, which are favorable for some applications such as transparent conductive oxide film. However, oxygen vacancy defects need to be carefully controlled in some applications such as TFTs, where the free carrier concentration should be controlled at a low level so that they can be depleted to achieve the off-state of the TFTs [18-20]. On the other hand, oxygen vacancy defects with low coordination, that are neutrally or positively charged, serve as deep trap states in the band gap. They may deteriorate or cause instability of the film properties. For instance, they may deteriorate the subthreshold characteristics and induce instability of the oxide TFTs [21]. This kind of oxygen vacancy defects should be suppressed. Annealing treatment after film deposition has been reported to be an effective way to reduce the defects and improve the crystallinity [22-27]. There have been some reports regarding the post-annealing effects on $\mathrm{ZnO}$ film grown by conventional thermal ALD and other techniques [18,28-32]. However, the annealing effects on sALD-ZnO film are seldom reported. In fact, the post-annealing conditions are crucial for improving the film properties. In this study, $\mathrm{ZnO}$ films with thickness of $100 \mathrm{~nm}$ were prepared by a high-deposition-rate sALD process, which has similar gain per cycle (GPC) values $(\sim 0.95 \AA$ Acycle) to other ALD processes [33,34]. However, it costs only $4 \mathrm{~s}$ for one sALD cycle, and tens of seconds for one plasma-enhanced or thermal ALD cycle [35,36]. As a result, it spends about $70 \mathrm{~min}$ to obtain an 100-nm-thick ZnO film by an sALD process, whereas it spends at least several times longer to obtain similar film thickness by other ALD techniques. Therefore, the sALD process is more promising for industrial applications. After film deposition, the films were subjected to a post-annealing process. It was found that the oxygen vacancy defects were suppressed by the annealing process. The effects on the film properties were also analyzed. An effective way to suppress the oxygen vacancy defects is provided in this work and might be useful for some applications.

\section{Materials and Methods}

$\mathrm{ZnO}$ films were grown on quartz substrate, or silicon wafer by a spatial ALD facility using diethylzinc (DEZ) and deionized water $\left(\mathrm{H}_{2} \mathrm{O}\right)$ vapor as precursors at a substrate temperature of $90^{\circ} \mathrm{C}$. The substrate was placed beneath the spray heads at a distance of $0.3 \mathrm{~mm}$ and moved back and forth at a speed of $15 \mathrm{~cm} / \mathrm{s}$. The parameters for the film deposition and annealing process are summarized in Table 1. Other detailed descriptions of the film deposition process have been reported elsewhere [37]. The $\mathrm{ZnO}$ films were annealed at $300-80{ }^{\circ} \mathrm{C}$ in an air ambient for $1 \mathrm{~h}$ at each temperature separately by a thermal annealing process (TAP) after deposition. 
Table 1. Parameters for the deposition and annealing process of spatial atomic layer deposition (sALD) $\mathrm{ZnO}$ film.

\begin{tabular}{cc}
\hline Parameter & Value \\
\hline Substrate temperature $\left({ }^{\circ} \mathrm{C}\right)$ & 90 \\
Moving speed of substrate holder $(\mathrm{cm} / \mathrm{s})$ & 15 \\
Gap between spray and substrate $(\mathrm{mm})$ & 0.3 \\
Flow rate of $\mathrm{H}_{2} \mathrm{O}$ carry gas $(\mathrm{sccm})$ & 400 \\
Flow rate of $\mathrm{H}_{2} \mathrm{O}$ dilute gas $(\mathrm{sccm})$ & 800 \\
Flow rate of DEZ carry gas $(\mathrm{sccm})$ & 100 \\
Flow rate of DEZ dilute gas $(\mathrm{sccm})$ & 3000 \\
Concentration of DEZ precursor $\left(\mathrm{cc} / \mathrm{cm}^{3}\right)$ & 40 \\
Annealing ambient & air \\
Annealing temperature $\left({ }^{\circ} \mathrm{C}\right)$ & $300-800$ \\
\hline
\end{tabular}

The film thickness $(t)$ was measured by an ellipsometer (M-2000, J. A. Woollam Co., Inc., Lincoln, NE, USA). The refractive index $(n)$ of the $\mathrm{ZnO}$ film grown on silicon wafer was obtained by a spectroscopic ellipsometer in the wavelength range of 350-800 $\mathrm{nm}$. The $n$ value of $\mathrm{ZnO}$ film was evaluated by an air roughness model, which was built up by a four-layer structure consist of "air, air/ZnO, $\mathrm{ZnO}$, silicon substrate", where the $\mathrm{ZnO}$ layer was fitted by a Tauc-Lorentz model. The $\mathrm{ZnO}$ films were grown on quartz substrate for the measurements of the transmittance $(T)$ and reflectance $(R)$ spectra using a spectrometer (MFS-630, Hong-Ming Technology, New Taipei City, Taiwan) in the wavelength of 380-1000 nm taking the air as the background. The light was incident from the air to the film. The crystal structure of the $\mathrm{ZnO}$ films was characterized by grazing-incidence $\mathrm{X}$-ray diffraction (GIXRD, Rigaku TTRAXIII, Ibaraki, Japan) spectra with an X-ray wavelength of $0.154 \mathrm{~nm}$ and a minimum scanning step of $0.02^{\circ}$. The chemical states of the elements were analyzed by an X-ray photoelectron spectroscope (XPS, ESCALAB 250Xi, Thermo Fisher, Waltham, MA, USA) equipped with an $\mathrm{Al}$ anode $(\mathrm{Al}-\mathrm{K} \alpha)$ in a wide range of binding energy. The morphology of the film surface was observed by a field-emission scanning electron microscope (FESEM sigma 500, Zeiss, Oberkochen, Germany). The electrical properties of the films were detected by a Hall effect measurement system (HMS5000, Side Semiconductor Technology, Shanghai, China).

\section{Results and Discussion}

As shown in Figure 1, the film thickness increases with annealing temperature. Usually, annealing treatment would cause structural relaxation and densification of the film, resulting in the decrease of film thickness. In this case, the increase of film thickness should be ascribed to the increment of oxide layer and will be further discussed in the XPS results.

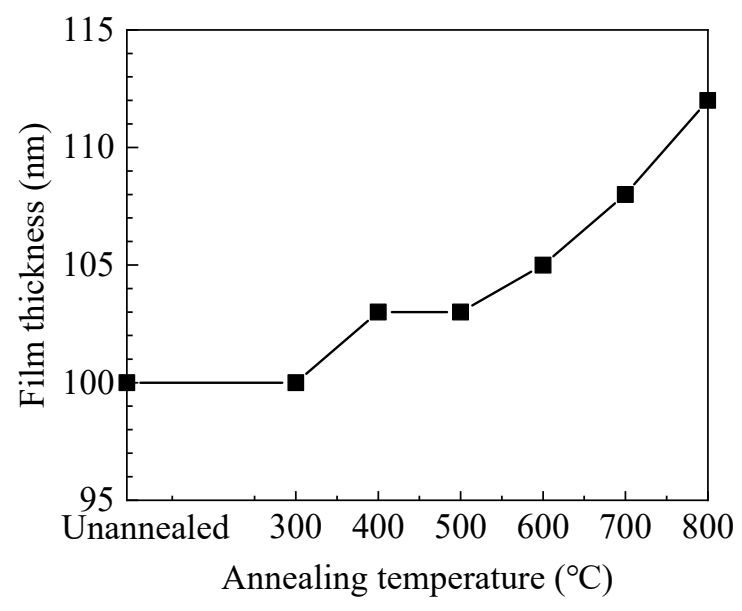

Figure 1. The variation of film thickness with annealing temperature. 
Figure 2a shows the wavelength-dependent refractive index $(n)$ of sALD-ZnO films on silicon wafer. In some applications such as solar cells, the refractive index at $630 \mathrm{~nm}$ is often concerned, so it is shown as a function of annealing temperature. The value of $\approx 1.95$ at $630 \mathrm{~nm}$ is in accordance with those reported in the literature $[12,34,38]$. In addition, the refractive index continuously increases with annealing temperature at $300-700{ }^{\circ} \mathrm{C}$, then slightly decreases at $800{ }^{\circ} \mathrm{C}$. The variation of refractive index can be a reflection of the change in the film density since they are closely related [38,39]. Namely, the film density increases with annealing temperature at $300-700{ }^{\circ} \mathrm{C}$, then slightly decreases at $800^{\circ} \mathrm{C}$. It is possible that annealing at $300-700^{\circ} \mathrm{C}$ induces structural relaxation and densification of the film, and hence increasing the refractive index. Another possible reason for the increase of refractive index can be the enhancement in crystallinity as indicated by the XRD and scanning electron microscopy (SEM) results. However, annealing at $800{ }^{\circ} \mathrm{C}$ might cause out-diffusion of zinc or oxygen atoms, leading to the decrease of refractive index [40-42]. The optical band gap $\left(E_{\mathrm{g}}\right)$ was also calculated from the refractive index at $630 \mathrm{~nm}$ according to the following model [43]:

$$
n^{2}=1+\left[13.6 /\left(E_{g}+3.4\right)\right]^{2}
$$

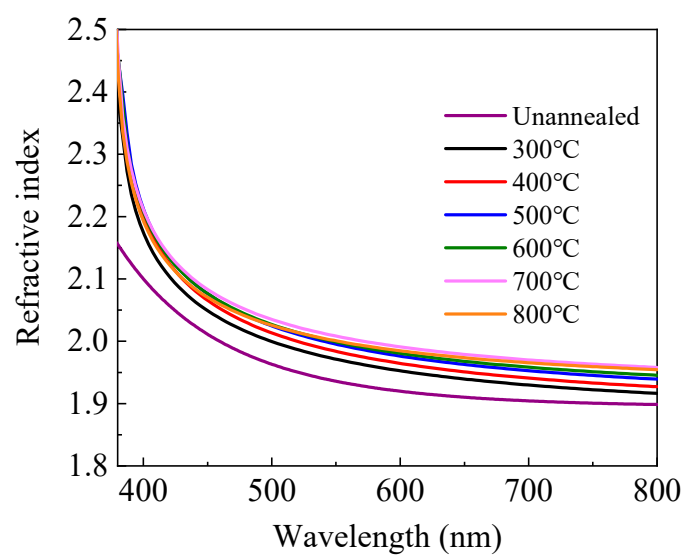

(a)

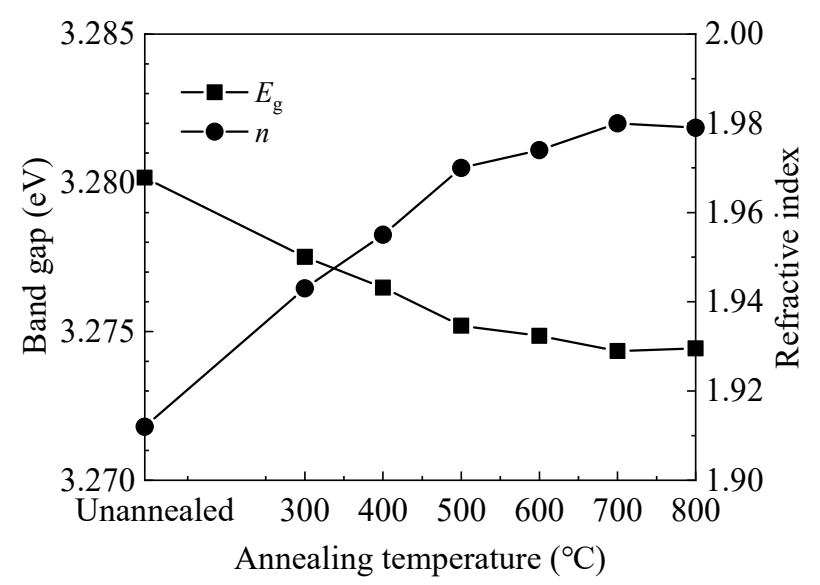

(b)

Figure 2. (a) The wavelength-dependent refractive index $(n)$ and (b) the variation of refractive index at $630 \mathrm{~nm}$ and band gap calculated from the refractive index with annealing temperature.

As shown in Figure 2b, the optical band gap decreases with increasing annealing temperature at $300-700{ }^{\circ} \mathrm{C}$, then slightly increases at $800^{\circ} \mathrm{C}$. The decrease of optical band gap can be ascribed to the non-degeneracy of the energy states caused by the decrease of carrier concentration according to the 
Burstein-Moss model $[12,44]$. Similarly, the slight increase of band gap at $800^{\circ} \mathrm{C}$ should be ascribed to the increase of carrier concentration.

Figure 3a shows the transmittance and reflectance spectra of $\mathrm{ZnO}$ /quartz samples annealed at different temperatures. The transmittance is high in the visible and near-infrared light range for all samples. It can be seen that the transmittance spectra change slightly with annealing temperature and exhibit an inverse correlation with the reflectance spectra. Therefore, the variation of transmittance spectra should be attributed primarily to the different reflection conditions caused by the different refractive indexes and film thicknesses of $\mathrm{ZnO}$ films annealed in different conditions. In addition, the transmittance dramatically decreases at the short wavelength around $400 \mathrm{~nm}$, which corresponds to the absorption caused by the band-to-band transition. The absorption edge shifts to the longer wavelength region after annealing, indicating the decrease of optical band gap $\left(E_{\mathrm{g}}\right)$. To verify this, the optical band gap was also extracted by Tauc's plot as expressed by the equation [45]:

$$
(\alpha \mathrm{h} v)^{2}=\mathrm{A}\left(\mathrm{h} v-E_{\mathrm{g}}\right)
$$

where $\alpha$ is the absorption coefficient, $\mathrm{h} v$ is the energy of the incident light, and $\mathrm{A}$ is a constant factor. Figure $3 \mathrm{~b}$ shows the dependence of the optical band gap on annealing temperature. The optical band gap and its developing trend are broadly in line with that calculated from the refractive index. The small fluctuation of the band gap value is probably due to the fitting error of the Tauc plots. The optical loss spectra have been calculated as expressed by $100-T-R$ to reflect the absorption and scattering of the incident light and plotted in Figure 3c. The optical loss is less than $2 \%$ in the range of $450-1000 \mathrm{~nm}$ for the unannealed sample and further decreases to less than $1 \%$ after annealing. Therefore, the optical loss does not have a significant effect on the transmittance spectra in the range of 450-1000 nm. However, it dramatically increases at the shorter wavelength (380-450 nm) due to the absorption by band-to-band transition, leading to the dramatic decrease of transmittance.

Figure 4a shows the GIXRD spectra of $\mathrm{ZnO}$ films deposited on silicon wafer. The diffraction peaks can be well identified to the (100), (002), (101), and (110) planes of the hexagonal wurtzite ZnO lattice, among which the (100) peak has the strongest intensity [46,47]. Moreover, a weak (002) peak is also observed for the unannealed and low-temperature $\left(300-500{ }^{\circ} \mathrm{C}\right)$ annealed films, then disappears at higher annealing temperature. This might be responsible for the increase of film resistivity as shown in the Hall effect results since the (002) plane is the most compact plane in the wurtzite $\mathrm{ZnO}$ lattice [48]. The intensity of other peaks increases with annealing temperature, indicating the increase of crystallinity. It is worth noting that the diffraction peaks shift with annealing temperature, which suggests a lattice expansion or contraction. Various micro-structural parameters such as crystallite size $(D)$, interplanar distance (d-spacing), microstrain $(\varepsilon)$, dislocation density $(\delta)$, and stacking fault probability $(\alpha)$ were also calculated from the XRD data and plotted in Figure $4 b-d[49,50]$. The average size of the (100)-orientated crystallites was estimated using Scherrer's equation [51]:

$$
D=k \lambda /(\beta \cos \theta)
$$

where $k$ is a shape factor, $\lambda$ is the wavelength of the $\mathrm{X}$-ray, $\beta$ and $\theta$ are the full width at half maximum (FWHM) and the Bragg angle of the $\left(\begin{array}{lll}1 & 0 & 0\end{array}\right)$ peaks, respectively. The interplanar distance of the $\left(\begin{array}{lll}1 & 0 & 0\end{array}\right)$ planes was calculated from the Bragg formula [52]:

$$
2 d \sin \theta=n \lambda
$$

where $d$ is the interplanar distance, $n$ is the order of diffraction. The microstrain $\varepsilon$ was calculated as:

$$
\varepsilon=\beta \cot \theta-\lambda /(D \sin \theta)
$$


where $D$ is the crystallite size of the preferentially (100)-orientated crystallites. The dislocation density $\delta$ was calculated as:

$$
\delta=n / D^{2}
$$

where $n$ is a factor. The stacking fault probability $(\alpha)$ was calculated as:

$$
\alpha=\left(2 \pi^{2} / 45 \sqrt{3}\right)[\Delta(2 \theta) / \tan \theta]
$$

where $\Delta(2 \theta)$ is the peak shift. Figure $4 \mathrm{~b}$ shows the variation of FWHM value and crystallite size with annealing temperature. The FWHM value decreases with increasing temperature. Accordingly, the crystallite size increases with increasing temperature. In addition, the increase of crystallite size is more significant at $700-800{ }^{\circ} \mathrm{C}$. The interplanar distance for the unannealed $\mathrm{ZnO}$ film is $\sim 2.795 \AA$, which is smaller than the standard value of $2.816 \AA$, suggesting a lattice contraction of the film, possibly due to the existence of a large number of oxygen vacancy defects in the lattice $[33,53]$. The interplanar distance increases with annealing temperature at $300-700{ }^{\circ} \mathrm{C}$, implying that the vacancy defects are repaired, possibly by absorbing oxygen atoms from the ambient. However, the interplanar distance slightly reduces when the annealing temperature further increases to $800{ }^{\circ} \mathrm{C}$, possibly due to the creation of new vacancy defects. Zn out-diffusion at similar annealing temperature $\left(900{ }^{\circ} \mathrm{C}\right)$ has been observed by other group [40-42]. Oxygen out-diffusion may be another possible reason for the decrease of interplanar distance as inferred from the XPS results. The development of interplanar distance is consistent with the variation of refractive index since the film density may be influenced by the vacancy defects. Accordingly, the microstrain releases as the annealing temperature increases mainly due to the restoration of the lattice contraction indicated by the shift of diffraction peaks to the standard position and the increase of interplanar distance approaches the standard value. The increase of crystallite size also contributes to the release of microstrain owing to the decrease of $\beta$ value. Therefore, the microstrain keeps decreasing at $800{ }^{\circ} \mathrm{C}$ regardless of the decrease of interplanar distance. The dislocation density decreases with increasing annealing temperature owing to the increase of crystallite size. The stacking fault probability decreases with increasing annealing temperature at $300-700{ }^{\circ} \mathrm{C}$ due to the reduction of the peak shift as well as the variance of interplanar distance compared with the standard value. Then, it slightly increases at $800{ }^{\circ} \mathrm{C}$ due to the out-diffusion of oxygen atoms.

Figure 5a shows the fully scanned XPS spectra of the $\mathrm{ZnO}$ films with different annealing temperatures. The observed peaks can be assigned to $\mathrm{Zn}$ or $\mathrm{O}$ element [54]. Figure $5 \mathrm{~b}$ shows the $\mathrm{O} 1$ s peak of the $\mathrm{ZnO}$ films annealed by different temperatures. The $\mathrm{O} 1$ s peak shifts towards the lower binding energy direction as the annealing temperature increases from 300 to $700{ }^{\circ} \mathrm{C}$, due to the filling of oxygen vacancies by absorbing oxygen from the ambient, leading to higher valence electron density around the oxygen and hence a stronger screening effect of the binding energy. However, the peak slightly shifts back to the higher binding energy direction when the annealing temperature further increases to $800^{\circ} \mathrm{C}$, suggesting more oxygen vacancy defects, possibly due to the out-diffusion of oxygen atoms from $\mathrm{ZnO}$ film at such a high annealing temperature. Figure $5 \mathrm{c}-\mathrm{h}$ shows the high-resolution spectra of $\mathrm{O} 1 \mathrm{~s}$ peaks for $\mathrm{ZnO}$ films annealed at $300-800{ }^{\circ} \mathrm{C}$. The $\mathrm{O} 1 \mathrm{~s}$ peak can be fitted by two constituent peaks. The peaks located at around $529.8 \mathrm{eV}\left(\mathrm{O}_{\mathrm{L}}\right)$ and $531.4 \mathrm{eV}$ $\left(\mathrm{O}_{\mathrm{D}}\right)$ are related to oxygen in a stoichiometric hexagonal wurtzite $\mathrm{ZnO}$ lattice and that with oxygen vacancy defects, respectively $[55,56]$. In the literature, a peak around $534.3 \mathrm{eV}$ related to the $\mathrm{OH}$ species or excess oxygen was observed in some cases [55]. However, it is almost unobservable in this case, implying that the precursors are completely reacted on the substrate surface, otherwise the $\mathrm{OH}$-related species would remain in the films. In addition, the area ratio of $\mathrm{O}_{\mathrm{D}} /\left(\mathrm{O}_{\mathrm{D}}+\mathrm{O}_{\mathrm{L}}\right)$ is calculated to indicate the concentration of oxygen vacancy defects. The area ratio decreases from $15.6 \%$ to $11.2 \%$ as the annealing temperature increases from 300 to $700{ }^{\circ} \mathrm{C}$, which also indicates the suppression of oxygen vacancy defects. In addition, the increase of film thickness, interplanar distance of (100) planes and refractive index serve as the secondary evidence since they can be possibly induced by the suppression of oxygen vacancy defects. The oxide layer may increase as more oxygen atoms are incorporated in 
the film, thus increasing the film thickness. The lattice contraction may restore as the oxygen vacancy defects are repaired, leading to the increase of interplanar distance. The film density is also expected to increase as the vacancy defects are suppressed, leading to the increase of refractive index. However, the area ratio increases to $11.8 \%$ when the annealing temperature further increases to $800{ }^{\circ} \mathrm{C}$ due to the out-diffusion of the oxygen atoms.

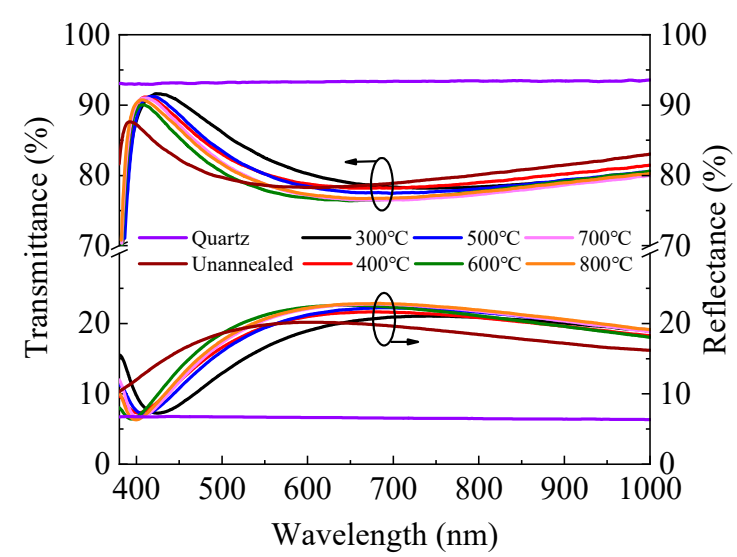

(a)

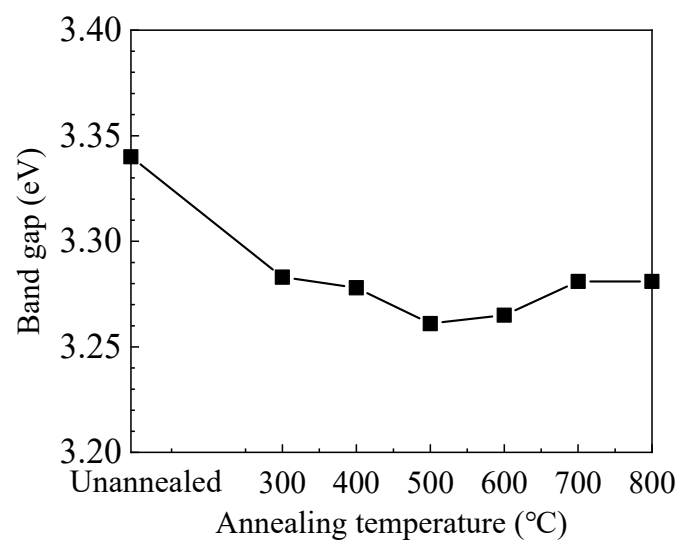

(b)

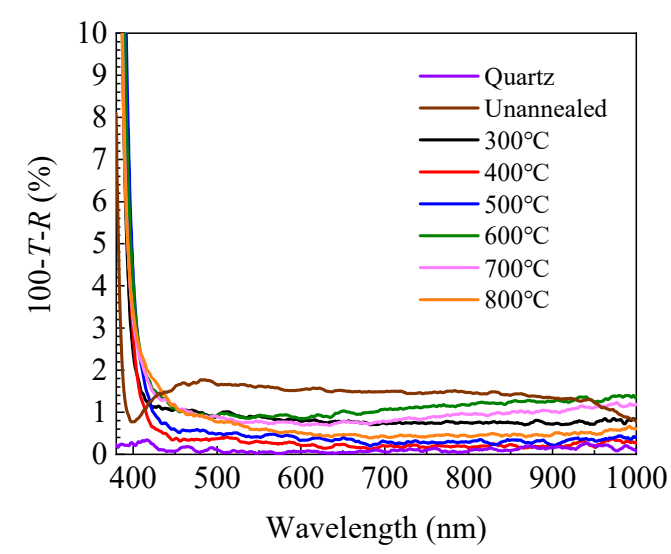

(c)

Figure 3. (a) Transmittance and reflectance spectra of sALD-ZnO films annealed at different temperatures; (b) dependence of optical band gap $\left(E_{\mathrm{g}}\right)$ of sALD ZnO films on annealing temperature; (c) optical loss spectra of sALD-ZnO films annealed at different temperatures. 
Figure 6 shows the FESEM images of the $\mathrm{ZnO}$ films deposited on silicon wafer and annealed at $300-800{ }^{\circ} \mathrm{C}$. The film surface seems to be consisted of rice-like grains and amorphous phase when annealed at $300{ }^{\circ} \mathrm{C}$. The grain size becomes larger accompanied by the transformation of amorphous phase to the crystalline phase as the annealing temperature increases, resulting in more compact film surface at high annealing temperature. The average lateral size of the grains was evaluated by the following method: firstly, a diagonal line was draw in the SEM images; then the number of grains under the diagonal line was counted out; finally, the average grain size was obtained by dividing the length of the diagonal line by the number of grains under it. The average lateral sizes of the grains were 21.0, 24.1, 30.2, 32.2, 45.3, $58 \mathrm{~nm}$ for the $\mathrm{ZnO}$ films annealed at $300,400,500,600,700$ and $800{ }^{\circ} \mathrm{C}$, respectively. The grain sizes were similar to the crystallite size estimated from Scherrer's equation for the samples annealed at $300-600^{\circ} \mathrm{C}$. However, they were significantly larger than the crystallite size for the samples annealed at higher temperature of $700-800^{\circ} \mathrm{C}$. In addition, the grain shape changed from rice-like (typical shape for $\mathrm{ZnO}$ crystallite) at $300-600{ }^{\circ} \mathrm{C}$ to polygonal at $700-800{ }^{\circ} \mathrm{C}$ [31]. Therefore, we infer that the crystallites coalesce to form larger grains at such a high annealing temperature.

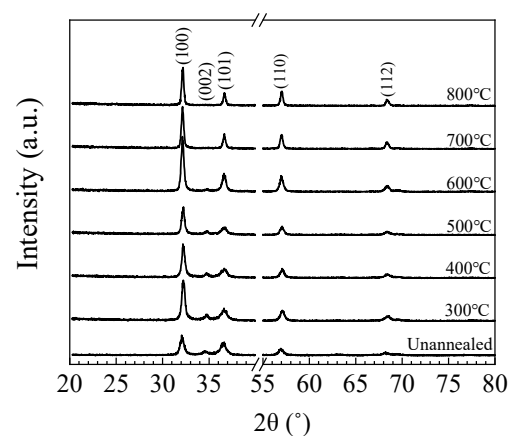

(a)

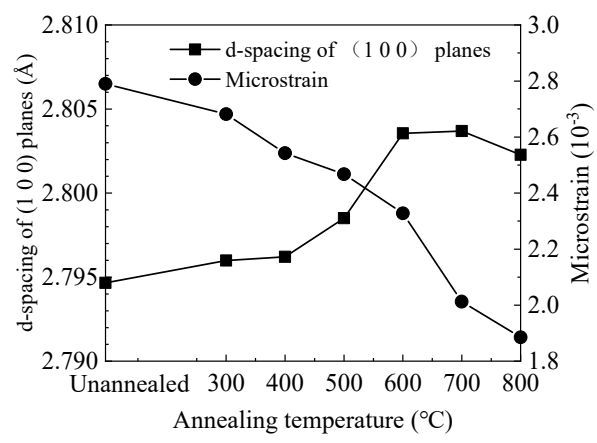

(c)

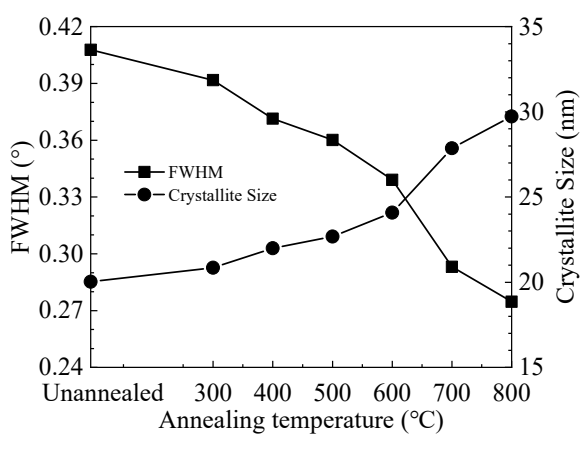

(b)

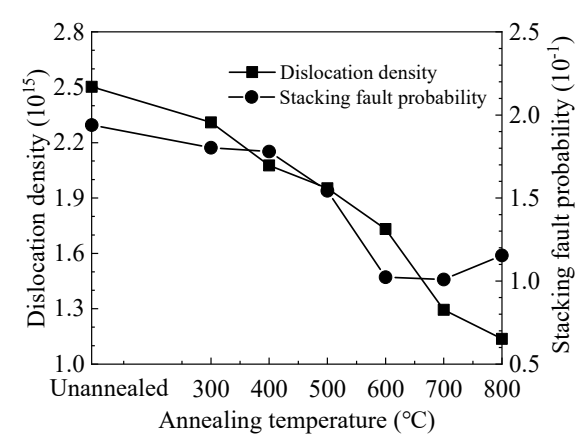

(d)

Figure 4. (a) Grazing-incidence X-ray diffraction (GIXRD) spectra of sALD-ZnO films annealed at different temperatures; (b) variation of full width at half maximum (FWHM) for the $\left(\begin{array}{lll}1 & 0 & 0\end{array}\right)$ peak and the crystallite size of sALD ZnO films with annealing temperature; dependence of (c) d-spacing of $\left(\begin{array}{lll}1 & 0 & 0\end{array}\right)$ planes, microstrain, (d) dislocation density and stacking fault probability on the annealing temperature.

Figure 7 shows the variation of resistivity, carrier concentration and mobility of the $\mathrm{ZnO}$ films with annealing temperature. We observe $n$-type conductivity for all films. The carrier concentration decreases with increasing annealing temperature at $300-700{ }^{\circ} \mathrm{C}$, then slightly increases at $800{ }^{\circ} \mathrm{C}$. Similar trends have been observed by other groups [57-59]. The decrease of carrier concentration should be ascribed to the suppression of oxygen vacancy defects since they have been identified as one of the origins of carrier concentration. In contrast, the increase of carrier concentration may be related to zinc or oxygen out-diffusion at $800{ }^{\circ} \mathrm{C}$. The mobility increases with annealing temperature owing to 
the increase of crystallinity and crystallite size. The resistivity of the film increases with annealing temperature at $300-700^{\circ} \mathrm{C}$, then decreases at $800^{\circ} \mathrm{C}$. The variation of film resistivity should be ascribed primarily to the variation of carrier concentration since they exhibit close inverse relation. The decrease of $\left(\begin{array}{lll}0 & 0 & 2\end{array}\right)$ peak with increasing annealing temperature may also play a part in the increase of film resistivity. The resistivity decreases at $800^{\circ} \mathrm{C}$ as the carrier concentration increases, which should be attributed to the oxygen out-diffusion at such a high temperature.

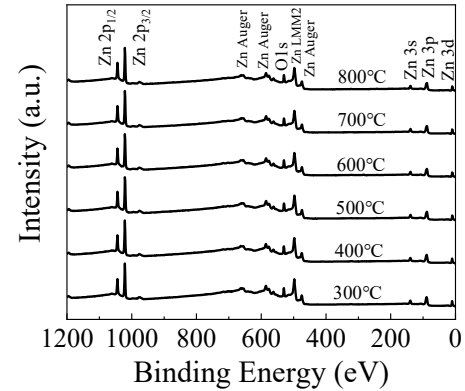

(a)

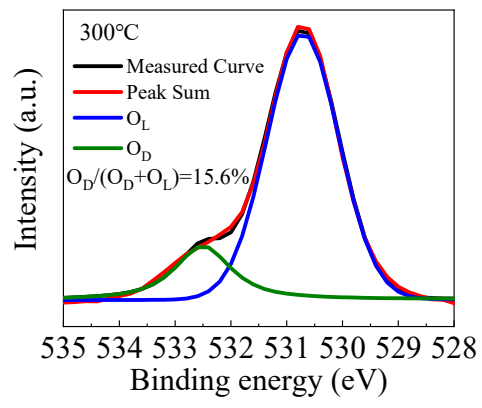

(c)

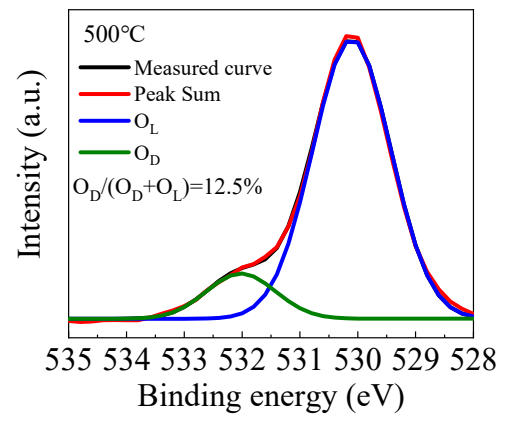

(e)

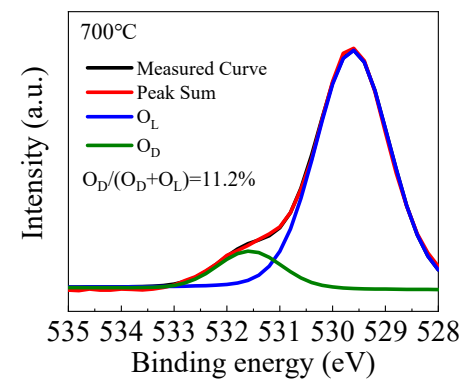

(g)

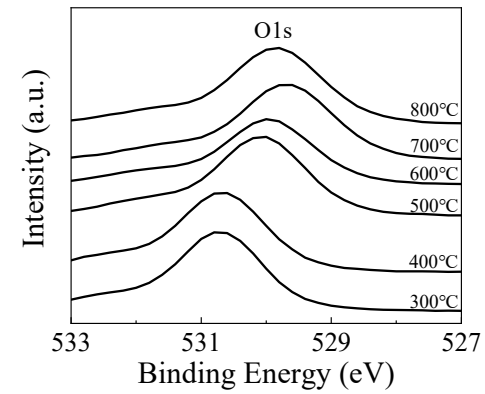

(b)

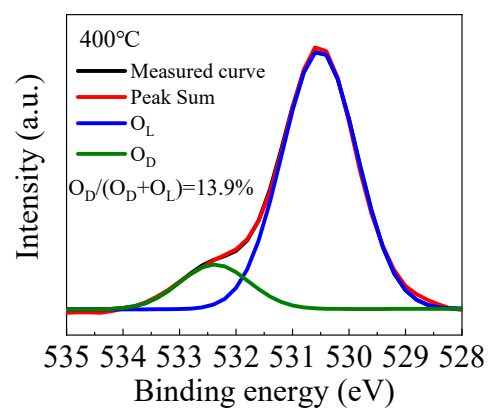

(d)

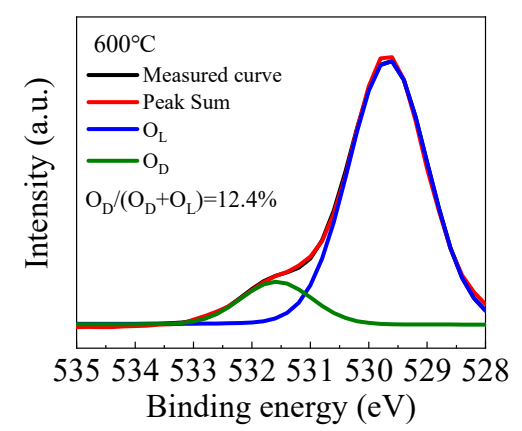

(f)

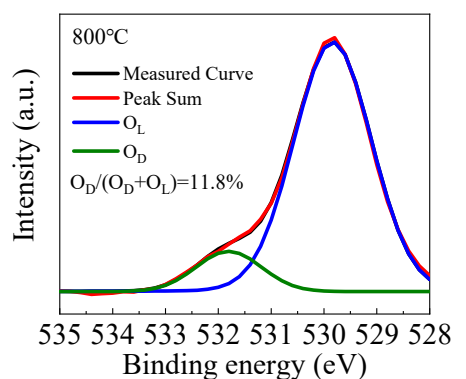

(h)

Figure 5. (a) The fully scanned X-ray photoelectron spectroscopy (XPS) spectra and (b) the O 1s peak of the sALD-ZnO films annealed at $300-800{ }^{\circ} \mathrm{C}$; (c-h) the high-resolution spectra of $\mathrm{O}$ 1s peak of the sALD ZnO films annealed at $300-800{ }^{\circ} \mathrm{C}$. 


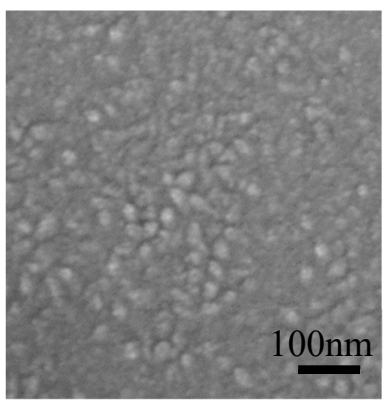

(a)

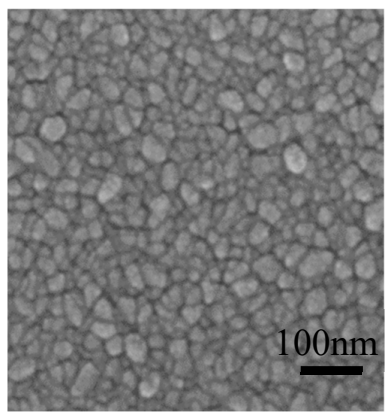

(c)

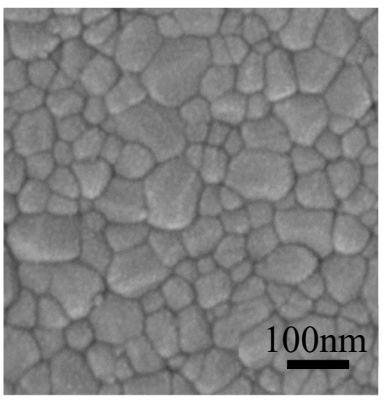

(e)

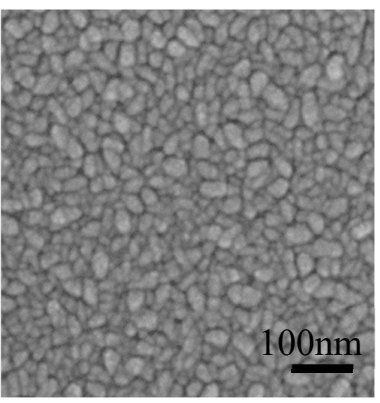

(b)

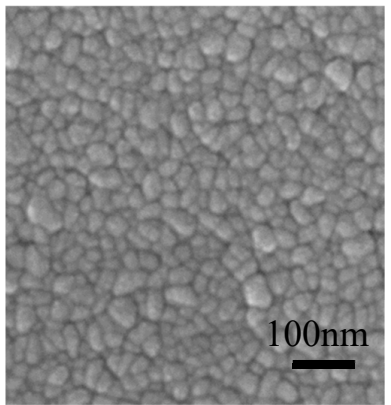

(d)

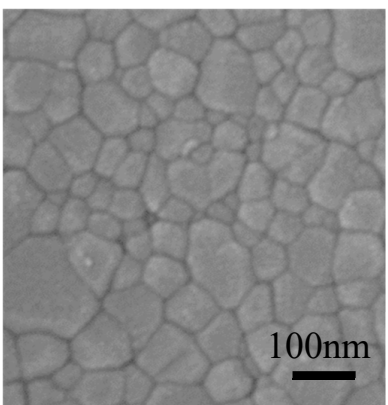

(f)

Figure 6. Field-emission scanning electron microscope (FESEM) images of sALD-ZnO films annealed at (a) $300{ }^{\circ} \mathrm{C}$, (b) $400{ }^{\circ} \mathrm{C}$, (c) $500{ }^{\circ} \mathrm{C}$, (d) $600{ }^{\circ} \mathrm{C}$, (e) $700{ }^{\circ} \mathrm{C}$, and (f) $800{ }^{\circ} \mathrm{C}$.

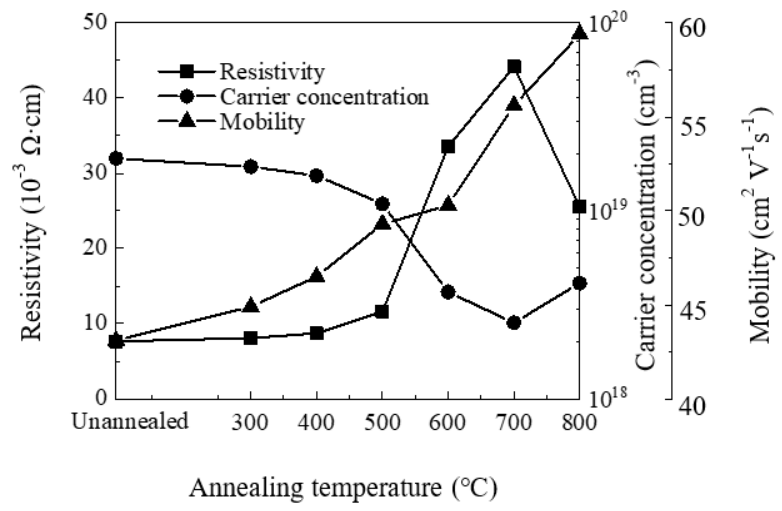

Figure 7. The variation of resistivity, carrier concentration and mobility of sALD-ZnO films with annealing temperatures. 


\section{Conclusions}

In this study, a 100-nm-thick ZnO film was prepared by a spatial ALD process with high deposition rate, which is promising for industrial applications. The oxygen vacancy defects in the $\mathrm{ZnO}$ film can be suppressed by annealing at $300-700{ }^{\circ} \mathrm{C}$ to improve the crystallinity and film properties, which might be helpful for some applications where oxygen vacancy defects are harmful and need to be suppressed. Annealing at a higher temperature of $800{ }^{\circ} \mathrm{C}$ might induce oxygen out-diffusion from the film and deteriorate the film properties. Therefore, it should be avoided in terms of suppressing the oxygen vacancy defects. In addition, the annealing process has little effect on the optical properties and a significant effect on the electrical properties of the $\mathrm{ZnO}$ film.

Author Contributions: Conceptualization, S.-Y.L. and M.-J.Z.; methodology, Z.-T.S. and Z.-X.Z.; formal analysis, S.-Y.L., M.-J.Z., W.-Y.W., X.-P.G.; writing—original draft preparation, M.-J.Z. and Z.-T.S.; writing-review and editing, S.-Y.L. and M.-J.Z.; funding acquisition, S.-Y.L., M.-J.Z. and W.-Z.Z. All authors have read and agreed to the published version of the manuscript.

Funding: This research was funded by the scientific research projects of Xiamen University of Technology, grant numbers YKJ19001R, 0105-50419030, and 30319003; the National Natural Science Foundation of China, grant numbers 21975260 and 61704142.

Conflicts of Interest: The authors declare no conflict of interest.

\section{References}

1. Zhang, P.; Wu, J.; Zhang, T.; Wang, Y.; Liu, D.; Chen, H.; Ji, L.; Liu, C.; Ahmad, W.; Chen, Z.D.; et al. Perovskite Solar Cells with ZnO Electron-Transporting Materials. Adv. Mater. 2017, 30, 1703737. [CrossRef] [PubMed]

2. Lin, Y.-Y.; Hsu, C.-C.; Tseng, M.-H.; Shyue, J.-J.; Tsai, F.-Y. Stable and High-Performance Flexible ZnO Thin-Film Transistors by Atomic Layer Deposition. ACS Appl. Mater. Interfaces 2015, 7, 22610-22617. [CrossRef] [PubMed]

3. Yang, Y.; Li, S.; Liu, F.; Zhang, N.; Liu, K.; Wang, S.; Fang, G. Bidirectional electroluminescence from $p-\mathrm{SnO}_{2} / i-\mathrm{MgZnO} / n-\mathrm{ZnO}$ heterojunction light-emitting diodes. J. Lumin. 2017, 186, 223-228. [CrossRef]

4. Zhu, L.; Zeng, W. Room-temperature gas sensing of ZnO-based gas sensor: A review. Sensors Actuators A Phys. 2017, 267, 242-261. [CrossRef]

5. Nelson, S.F.; Ellinger, C.R.; Levy, D.H. Improving Yield and Performance in ZnO Thin-Film Transistors Made Using Selective Area Deposition. ACS Appl. Mater. Interfaces 2015, 7, 2754-2759. [CrossRef]

6. Shewale, P.; Lee, S.; Yu, Y. UV sensitive pulsed laser deposited $\mathrm{ZnO}$ thin films: Influence of growth temperature. J. Alloy. Compd. 2018, 744, 849-858. [CrossRef]

7. Bang, K.; Son, G.-C.; Son, M.; Jun, J.-H.; An, H.; Baik, K.H.; Myoung, J.-M.; Ham, M. Effects of Li doping on the structural and electrical properties of solution-processed $\mathrm{ZnO}$ films for high-performance thin-film transistors. J. Alloy. Compd. 2018, 739, 41-46. [CrossRef]

8. Chen, S.; Wang, J.; Zhang, Z.; Briscoe, J.; Warwick, M.E.; Li, H.; Hu, P. Aerosol assisted chemical vapour deposition of conformal $\mathrm{ZnO}$ compact layers for efficient electron transport in perovskite solar cells. Mater. Lett. 2018, 217, 251-254. [CrossRef]

9. Husna, J.; Aliyu, M.M.; Islam, M.A.; Chelvanathan, P.; Hamzah, N.R.; Hossain, M.S.; Karim, M.; Amin, N. Influence of Annealing Temperature on the Properties of ZnO Thin Films Grown by Sputtering. Energy Procedia 2012, 25, 55-61. [CrossRef]

10. Wang, Y.; Kang, K.-M.; Kim, M.; Park, H.-H. Low temperature method to passivate oxygen vacancies in un-doped $\mathrm{ZnO}$ films using atomic layer deposition. Thin Solid Films 2018, 660, 852-858. [CrossRef]

11. Suja, M.; Bashar, S.B.; Morshed, M.M.; Liu, J. Realization of Cu-Doped p-Type ZnO Thin Films by Molecular Beam Epitaxy. ACS Appl. Mater. Interfaces 2015, 7, 8894-8899. [CrossRef] [PubMed]

12. Illiberi, A.; Roozeboom, F.; Poodt, P. Spatial Atomic Layer Deposition of Zinc Oxide Thin Films. ACS Appl. Mater. Interfaces 2011, 4, 268-272. [CrossRef] [PubMed]

13. Hoye, R.L.Z.; Muñoz-Rojas, D.; Nelson, S.; Illiberi, A.; Poodt, P.; Roozeboom, F.; MacManus-Driscoll, J.L. Research Update: Atmospheric pressure spatial atomic layer deposition of $\mathrm{ZnO}$ thin films: Reactors, doping, and devices. APL Mater. 2015, 3, 040701. [CrossRef] 
14. Kamiya, T.; Nomura, K.; Hirano, M.; Hosono, H. Electronic structure of oxygen deficient amorphous oxide semiconductor a-InGaZnO $\mathrm{In-x}_{\mathrm{x}}$ : Optical analyses and first-principle calculations. Phys. Status Solidi (c) 2008, 5, 3098-3100. [CrossRef]

15. Kamiya, T.; Nomura, K.; Hosono, H. Electronic structure of the amorphous oxide semiconductor a-InGaZnO ${ }_{4-x}$ : Tauc-Lorentz optical model and origins of subgap states. Phys. Status Solidi (a) 2009, 206, 860-867. [CrossRef]

16. Kim, J.-Y.; Oh, S.-A.; Yu, K.M.; Bae, B.-S.; Yun, E.-J. Transient photocurrent responses in amorphous Zn-Sn-O thin films. J. Korean Phys. Soc. 2015, 66, 1039-1044. [CrossRef]

17. Xu, J.; Liu, J.; Huang, B.; Li, S.N.; Liu, B.-X. The role of negatively charged oxygen vacancies upon $\beta-\mathrm{MnO}_{2}$ conductivity. Acta Mater. 2017, 131, 88-97. [CrossRef]

18. Ahn, C.H.; Woo, C.H.; Wang, H.; Lee, E.; Cho, H.K.; Cho, H.J.; Kim, T.-S. Influence of active layer thickness and annealing in zinc oxide TFT grown by atomic layer deposition. Surf. Interface Anal. 2010, 42, 955-958. [CrossRef]

19. Zhao, M.; Song, C.; Xu, Y.; Xu, D.; Zhang, J.; Wu, T.; Guo, R.; Chen, R. Back-Channel-Etched Oxide Thin Film Transistors with a Corrosion Resistant Crystalline InGaO Channel. ECS J. Solid State Sci. Technol. 2019, 8, Q80-Q84. [CrossRef]

20. Zhao, M.; Zhang, Z.; Xu, Y.; Xu, D.; Zhang, J.; Huang, Z. High-Performance Back-Channel-Etched Thin-Film Transistors with an InGaO/InZnO Stacked Channel. Phys. Status solidi (a) 2020, 217. [CrossRef]

21. Chen, W.-Y.; Chen, J.S.; Jeng, J.-S. Suppression of Oxygen Vacancy and Enhancement in Bias Stress Stability of High-Mobility ZnO Thin-Film Transistors with $\mathrm{N}_{2} \mathrm{O}$ Plasma Treated MgO Gate Dielectrics. ECS J. Solid State Sci. Technol. 2013, 2, P287-P291. [CrossRef]

22. Park, H.K.; Jo, J.; Hong, H.K.; Heo, J. Influence of post-deposition annealing on the electrical properties of zinc oxide thin films. Thin Solid Films 2014, 573, 22-26. [CrossRef]

23. Tian, J.; Wang, G.G.; Zhang, H.Y. Effect of Annealing Atmosphere on the Structural and Optical Properties of ZnO Thin Films on Si (100) Substrates Grown by Atomic Layer Deposition. J. Nano Res. 2015, 37, 92-98. [CrossRef]

24. Zhang, Y.; Lu, H.-L.; Geng, Y.; Sun, Q.-Q.; Ding, S.-J.; Zhang, D.W. Impact of rapid thermal annealing on structural and electrical properties of $\mathrm{ZnO}$ thin films grown atomic layer deposition on GaAs substrates. Vacuum 2014, 103, 1-4. [CrossRef]

25. Chandramohan, R.; Vijayan, T.; Arumugam, S.; Ramalingam, H.B.; Dhanasekaran, V.; Sundaram, K.; Mahalingam, T.; Vikraman, D. Effect of heat treatment on microstructural and optical properties of CBD grown Al-doped ZnO thin films. Mater. Sci. Eng. B 2011, 176, 152-156. [CrossRef]

26. Chandramohan, R.; Dhanasekaran, V.; Arumugam, R.; Sundaram, K.; Thirumalai, J.; Mahalingam, T. Physical properties evaluation of annealed $\mathrm{ZnAl}_{2} \mathrm{O}_{4}$ alloy thin films. Dig. J. Nanomater. Biostruct. 2012, 7, 1315-1325.

27. Saxena, P.; Gorji, N.E. COMSOL Simulation of Heat Distribution in Perovskite Solar Cells: Coupled Optical-Electrical-Thermal 3-D Analysis. IEEE J. Photovolt. 2019, 9, 1693-1698. [CrossRef]

28. Wang, A.; Chen, T.; Lu, S.; Wu, Z.; Li, Y.; Chen, H.; Wang, Y. Effects of doping and annealing on properties of $\mathrm{ZnO}$ films grown by atomic layer deposition. Nanoscale Res. Lett. 2015, 10, 75. [CrossRef]

29. Kim, C.; Lee, J.; Heo, J.; Shin, C.; Lee, T.; Park, J.; Ryu, H.H.; Chang, J.; Son, C. Effects of annealing temperature and $\mathrm{Al}_{2} \mathrm{O}_{3}$ buffer layer on $\mathrm{ZnO}$ thin films grown by atomic layer deposition. Curr. Appl. Phys. 2010, 10, S298-S301. [CrossRef]

30. Tian, J.-L.; Zhang, H.-Y.; Wang, G.-G.; Wang, X.-Z.; Sun, R.; Jin, L.; Han, J.-C. Influence of film thickness and annealing temperature on the structural and optical properties of $\mathrm{ZnO}$ thin films on $\mathrm{Si}$ (100) substrates grown by atomic layer deposition. Superlattices Microstruct. 2015, 83, 719-729. [CrossRef]

31. Lim, J.; Lee, C. Effects of substrate temperature on the microstructure and photoluminescence properties of ZnO thin films prepared by atomic layer deposition. Thin Solid Films 2007, 515, 3335-3338. [CrossRef]

32. Yen, C.-Y.; Jian, S.-R.; Chen, G.-J.; Lin, C.-M.; Lee, H.-Y.; Ke, W.-C.; Liao, Y.-Y.; Yang, P.-F.; Wang, C.-T.; Lai, Y.-S.; et al. Influence of annealing temperature on the structural, optical and mechanical properties of ALD-derived ZnO thin films. Appl. Surf. Sci. 2011, 257, 7900-7905. [CrossRef]

33. Cai, J.; Ma, Z.; Wejinya, U.; Zou, M.; Liu, Y.; Zhou, H.; Meng, X. A revisit to atomic layer deposition of zinc oxide using diethylzinc and water as precursors. J. Mater. Sci. 2018, 54, 5236-5248. [CrossRef] 
34. Nandakumar, N.; Dielissen, B.; Garcia-Alonso, D.; Liu, Z.; Gortzen, R.; Kessels, W.M.M.; Aberle, A.G.; Hoex, B. Resistive Intrinsic ZnO Films Deposited by Ultrafast Spatial ALD for PV Applications. IEEE J. Photovolt. 2015, 5, 1462-1469. [CrossRef]

35. Thomas, M.A.; Cui, J.B. Highly Tunable Electrical Properties in Undoped ZnO Grown by Plasma Enhanced Thermal-Atomic Layer Deposition. ACS Appl. Mater. Interfaces 2012, 4, 3122-3128. [CrossRef]

36. Yousfi, E.B.; Fouache, J.; Lincot, D. Study of atomic layer epitaxy of zinc oxide by in-situ quartz crystal microgravimetry. Appl. Surf. Sci. 2000, 153, 223-234. [CrossRef]

37. Zhao, M.-J.; Sun, Z.-T.; Hsu, C.-H.; Huang, P.-H.; Zhang, X.; Wu, W.-Y.; Gao, P.; Qiu, Y.; Lien, S.-Y.; Zhu, W.-Z. Zinc Oxide Films with High Transparency and Crystallinity Prepared by a Low Temperature Spatial Atomic Layer Deposition Process. Nanomaterials 2020, 10, 459. [CrossRef]

38. Pung, S.-Y.; Choy, K.; Hou, X. Growth of (002)-oriented $\mathrm{ZnO}$ thin films on largely lattice-mismatched substrates using atomic layer deposition. Int. J. Nanotechnol. 2013, 10, 247. [CrossRef]

39. Yao, J.K.; Huang, H.L.; Ma, J.Y.; Jin, Y.X.; Zhao, Y.A.; Shao, J.D.; He, H.B.; Yi, K.; Fan, Z.X.; Zhang, F.; et al. High refractive index $\mathrm{TiO}_{2}$ film deposited by electron beam evaporation. Surf. Eng. 2009, 25, 257-260. [CrossRef]

40. Wang, Z.; Luo, C.; Anwand, W.; Wagner, A.; Butterling, M.; Rahman, M.A.; Phillips, M.R.; Ton-That, C.; Younas, M.; Su, S.; et al. Vacancy cluster in ZnO films grown by pulsed laser deposition. Sci. Rep. 2019, 9, 3534. [CrossRef]

41. Ling, F.C.C.; Luo, C.Q.; Wang, Z.L.; Anwand, W.; Wagner, A. Zn-vacancy related defects in ZnO grown by pulsed laser deposition. Oxide Based Mater. Devices VIII 2017, 10105, 101050F. [CrossRef]

42. Wang, Z.; Su, S.; Ling, F.C.-C.; Anwand, W.; Wägner, A. Thermal evolution of defects in undoped zinc oxide grown by pulsed laser deposition. J. Appl. Phys. 2014, 116, 033508. [CrossRef]

43. Hervé, P.; Vandamme, L. General relation between refractive index and energy gap in semiconductors. Infrared Phys. Technol. 1994, 35, 609-615. [CrossRef]

44. Kim, W.-H.; Maeng, W.J.; Kim, M.-K.; Kim, H. Low Pressure Chemical Vapor Deposition of Aluminum-Doped Zinc Oxide for Transparent Conducting Electrodes. J. Electrochem. Soc. 2011, 158, D495-D499. [CrossRef]

45. Tauc, J. Optical properties and electronic structure of amorphous Ge and Si. Mater. Res. Bull. 1968, 3, 37-46. [CrossRef]

46. Kazmierczak-Balata, A.; Bodzenta, J.; Guziewicz, M. Microscopic investigations of morphology and thermal properties of $\mathrm{ZnO}$ thin films grown by atomic layer deposition method. Ultramicroscopy 2020, 210, 112923. [CrossRef]

47. Park, K.-H.; Han, G.D.; Kim, B.J.; Kang, E.H.; Park, J.S.; Shim, J.H.; Park, H.-D. Effects of atomic layer deposition conditions on the formation of thin $\mathrm{ZnO}$ films and their photocatalytic characteristics. Ceram. Int. 2019, 45, 18823-18830. [CrossRef]

48. Pung, S.-Y.; Choy, K.; Hou, X.; Shan, C. Preferential growth of ZnO thin films by the atomic layer deposition technique. Nanotechnology 2008, 19, 435609. [CrossRef]

49. Vikraman, D.; Park, H.J.; Kim, S.-I.; Thaiyan, M. Magnetic, structural and optical behavior of cupric oxide layers for solar cells. J. Alloy. Compd. 2016, 686, 616-627. [CrossRef]

50. Sebastian, S.; Kulandaisamy, I.; Valanarasu, S.; Yahia, I.S.; Kim, H.-S.; Vikraman, D. Microstructural and electrical properties evaluation of lead doped tin sulfide thin films. J. Sol Gel Sci. Technol. 2019, 93, 52-61. [CrossRef]

51. Muniz, F.; Miranda, M.A.R.; Dos Santos, C.M.; Sasaki, J. The Scherrer equation and the dynamical theory of X-ray diffraction. Acta Crystallogr. Sect. A Found. Adv. 2016, 72, 385-390. [CrossRef] [PubMed]

52. Pope, C.G. X-Ray Diffraction and the Bragg Equation. J. Chem. Educ. 1997, 74, 129. [CrossRef]

53. Tynell, T.; Karppinen, M. Atomic layer deposition of ZnO: A review. Semicond. Sci. Technol. 2014, $29,043001$. [CrossRef]

54. Boryło, P.; Matus, K.; Lukaszkowicz, K.; Kubacki, J.; Balin, K.; Basiaga, M.; Szindler, M.; Mikuła, J. The influence of atomic layer deposition process temperature on $\mathrm{ZnO}$ thin film structure. Appl. Surf. Sci. 2019, 474, 177-186. [CrossRef]

55. Yao, R.; Zheng, Z.; Zeng, Y.; Liu, X.; Ning, H.; Hu, S.; Tao, R.; Chen, J.; Cai, W.; Xu, M.; et al. All-Aluminum Thin Film Transistor Fabrication at Room Temperature. Materials 2017, 10, 222. [CrossRef] [PubMed] 
56. Luo, D.; Xu, H.; Zhao, M.; Li, M.; Xu, M.; Zou, J.; Tao, H.; Wang, L.; Peng, J. Influence of Source and Drain Contacts on the Properties of Indium-Gallium-Zinc-Oxide Thin-Film Transistors based on Amorphous Carbon Nanofilm as Barrier Layer. ACS Appl. Mater. Interfaces 2015, 7, 3633-3640. [CrossRef]

57. Cheng, Y.-C.; Yuan, K.-Y.; Chen, M.-J. Influence of homo-buffer layers and post-deposition rapid thermal annealing upon atomic layer deposition grown $\mathrm{ZnO}$ at $100{ }^{\circ} \mathrm{C}$ with three-pulsed precursors per growth cycle. J. Cryst. Growth 2017, 475, 39-43. [CrossRef]

58. Lee, C.M.; Cho, Y.J.; Kim, H.J.; Lee, W.W.; Kim, H.W.; Hwangbo, C.K.; Lee, J.G. Effects of Post-Annealing on the Electrical and Optical Properties of $\mathrm{ZnO}$ Thin Films Grown on $\mathrm{Al}_{2} \mathrm{O}_{3}$ Substrates by Atomic Layer Epitaxy. Mater. Sci. Forum 2007, 544, 729-732. [CrossRef]

59. Ke, L.; Lai, S.C.; Ye, J.D.; Kaixin, V.L.; Chua, S.J. Point defects analysis of zinc oxide thin films annealed at different temperatures with photoluminescence, Hall mobility, and low frequency noise. J. Appl. Phys. 2010, 108, 84502. [CrossRef]

(C) 2020 by the authors. Licensee MDPI, Basel, Switzerland. This article is an open access article distributed under the terms and conditions of the Creative Commons Attribution (CC BY) license (http://creativecommons.org/licenses/by/4.0/). 